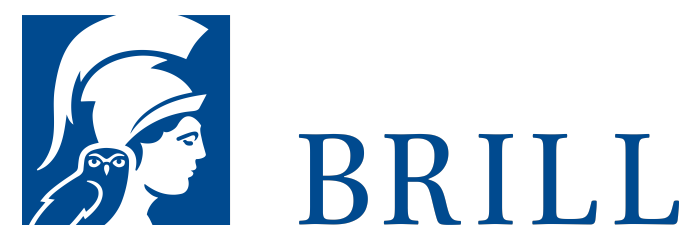

\title{
Human Centered Design
}

Innovationen entwickeln, statt Trends zu folgen

Author: Martin Ludwig Hofmann

Design als Innovationsgenerator: Die nächste industrielle Revolution beginnt ... genau jetzt. Warten Sie nicht länger auf den nächsten heißen Trend, dem Sie folgen können. Entwickeln Sie selbst Innovationen, die diesen Namen verdienen! Human Centered Design versteht sich als Verbindung aus kreativer Gestaltung, humanwissenschaftlicher Fundierung und experimentellem Arbeiten - und öffnet sich dabei bewusst einem interdisziplinären Blickwinkel. Martin Ludwig Hofmann führt in die Methodik des Human Centered Design ein und erläutert die Haltung, die diesem erweiterten Designverständnis zugrunde liegt. Eine intellektuelle Tour de Force von Apple über Adorno, von Naoto Fukasawa über Michel Foucault, von Paul Virilio bis zum kalifornischen Designbüro IDEO. Was Gestalter tun, ist in einem hohen Maße gesellschaftlich relevant. Es wird Zeit, dass wir uns dessen bewusst werden.

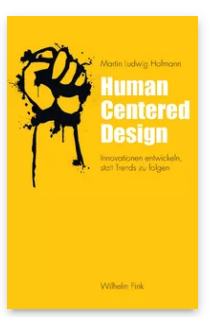

Pages: 187 Seiten, $29 \mathrm{~s} / \mathrm{w}$ Abb.

Language:

German

Subjects:

Architecture, Art

History

Publisher: Brill |

Fink

E-Book (PDF)

Released online:

04 Sep 2017

ISBN: $978-3^{-}$

8467-6286-8

List price

Hardback

Publication date:

14Jul 2017

ISBN: $978-3^{-}$

7705-6286-2

List price 
Martin Ludwig Hofmann ist Professor für

Humanwissenschaften im Kontext der Gestaltung an der

Hochschule Ostwestfalen-Lippe. Für seine Arbeiten als

Kreativdirektor wurde er international und national vielfach ausgezeichnet.

For more information see brill.com

Order information: Order online at brill.com

+44330333 0049 | customerservices@brill.com

Submission information: brill.com/authors

Titles published by Brill | Fink, Brill | mentis or Brill | Schöningh: +49(o)71 5413279216 | brill@brocom.de 